\title{
Linguistic discrimination on campus: Ratings of and attitudes toward student writing with African-American English
}

\author{
Ho’omana Nathan Horton*
}

\begin{abstract}
Based on empirical evidence, this study identifies a contradiction between attitudes towards the use of African-American English in student writing vs. how such writing is actually rated by university English instructors. Even when instructors expressed highly positive views of the use of stigmatized varieties of English in student essays, a statistically significant difference $(\mathrm{p}=0.027)$ was found between their ratings of essays with and without features of African-American English. These findings indicate that university instructors, even those who are consciously aware that linguistic discrimination is problematic, are not immune to the effects of linguistic discrimination. These results highlight the importance of dialect education and awareness programs for university English instructors as well as the need for further research into the prevalence of standard language ideology and linguistic discrimination at the university level.
\end{abstract}

Keywords. writing assessment; African-American English; language attitudes; standard language ideology; linguistic discrimination

1. Introduction. When it comes to language variation, university English instructors can easily find themselves in a tight ideological and pedagogical spot. Many university English instructors are vocal advocates of cultural diversity, actively working against discrimination on cultural grounds both in their department and at a wider level throughout the university and society. On the other hand, many instructors may also view themselves as the primary defenders and, perhaps accurately, as the primary providers of the English that students will need to be successful in their future academic careers, preferring or insisting upon the use of "Standard English" in their classrooms. The way that instructors handle this tension in their grading and teaching is vital, since at most universities, every undergraduate student is required to take an English composition class, and because the broader populace often looks to English teachers as the authority on how to address language variety.

Attitudes and ideologies about language variation have long been the subject of both linguistic and sociological investigation and the United States, like many other western cultures, has been shown to maintain a culture of standard language ideology, the idea that there is one standard or "correct" version of English (Lippi-Green 1997; Milroy \& Milroy 2012). Linguists and other social scientists have shown how this standard language ideology affects speakers of less prestigious varieties in many areas of life, from customer service positions (Eustace 2012) to speech pathology (Kroll, Mok, Keegan, Papakyritsis, \& Damico 2014). Despite these consistent findings, the prevalence and effects of standard language ideology in higher education has largely been unaddressed empirically and is only recently beginning to garner attention.

\footnotetext{
${ }^{*}$ I am grateful for the guidance and support of Dr. Stephanie Link and Dr. Dennis Preston in designing and carrying out this study, for the helpful comments of numerous Friends Of Oklahoma Language Sciences (FOOLS) attendees, and to the English Department instructors who participated in this study.

Author: Ho’omana Nathan Horton, Oklahoma State University (nathan.horton@okstate.edu)
} 
Johnson and VanBrackle (2012) investigated instructor treatment of linguistic variation in writing and found that anonymous raters of a state-mandated university admissions essay showed substantial linguistic discrimination against features of African-American English (AAE), rating essays with these features even more negatively than essays with Standard English errors. These findings clearly demonstrate that standard language ideology persists in academia and affects student writing. However, because the raters were anonymous, Johnson and VanBrackle were unable to investigate the relationship between raters' education level, teaching experience, experience with stigmatized dialects, or other demographic variables. Dunstan and Jaeger (2015) explored the influence of standard language ideology on university students and found that the academic experience of speakers of stigmatized dialects is often substantially negatively affected as a direct result of their use of these dialects. Although the use of stigmatized dialects by students clearly affects the way they are treated, both in writing and in other ways, few studies have empirically investigated the effects of stigmatized features on university English instructors' evaluation of student writing; to my knowledge, no one has investigated the relationship between English instructors' explicit attitudes and their treatment of stigmatized features in writing. Such research can provide important insights into the status of stigmatized varieties in the university English classroom and may have significant pedagogical implications.

This study aims to investigate whether the presence of morphosyntactic (that is, grammatical) features of African-American English in student writing affects the rating of student essays by instructors in the English department at a large public research university in the Upper South. This study also examines these instructors' conscious beliefs about the use of features from stigmatized varieties in student writing and compare their stated attitudes to their grading of student essays. In order to examine the effects of features of AAE on instructor rating, university English instructors were asked to rate one of two essays which are identical in content and organization and vary only in that one contains AAE features. In addition, I explored these instructors' conscious awareness of and beliefs about the use of stigmatized varieties in academic contexts.

2. Methods. This study adopted an embedded mixed-methods design with an emphasis on quantitative data (see Creswell 2013). This design allowed for simultaneous collection of both quantitative data and qualitative data, which was used to supplement and more deeply explore the quantitative findings. The participants in this study were 14 English Department graduate students who teach first-year English composition courses to undergraduate students. Further description of the participants can be found in section 2.1 below. Data collection involved an online survey which included a rating task in which participants were asked to holistically rate student essays on a scale of 0-4 (the standard university grading scale) and an attitudes questionnaire which investigated instructors' attitudes toward the use of stigmatized varieties of English. The attitudes questionnaire uses primarily Likert-scale ratings, but also includes openended follow-up questions in order to help explain instructors' reasoning behind the attitudes that they hold. The instrument and data collection procedures are described in detail in section 2.2. The ratings of the essays were analyzed using an independent samples t-test, while the attitudes questionnaire and follow-up questions were analyzed qualitatively and related to the findings of the rating section. The analysis methods are described in more detail in section 2.3 and the findings of these analyses are detailed in section 3. 
2.1. PARTICIPANTS. Participants in this study were all graduate students who are teaching assistants in the English Department at a large public research university in the Upper South of the United States, Upper South State University (USSU). All of these instructors teach English composition courses for American undergraduate students. The respondents consisted of three females and eleven males. Twelve of the respondents identify as White, one identifies as Black or African-American, and one identifies as American Indian or Alaska Native. Five of the respondents indicated that they have been teaching English at the university level for 0-3 years, and nine indicated that they have been teaching English at the university level for 4-9 years. In my experience as a graduate teaching assistant in this department, this is a fairly representative sample of the department's graduate teaching assistants, who teach the majority of the English composition courses for undergraduate students.

2.2. Data COLleCtion. All of the participants in this study are personal acquaintances of mine, and were asked individually to complete the survey. Instructors were informed only that the purpose of the survey was "to help us better understand how instructors rate student essays at [USSU]." The rating task and attitudes questionnaire were administered using the online survey software Qualtrics. The survey consists of three sections. The first section of the survey requests demographic information, including the residence history, teaching position, and teaching experience of the instructor. The second section of the survey presents instructors with the rating task. This section alternately displays one of two essays which are identical in content and vary only in that one essay includes morphosyntactic features of African-American English (AAE). The original and modified essays along with the list of modifications can be found in Appendix A. Participants were informed that the essay was a sample of authentic undergraduate writing which was written during a timed writing assignment, and were asked to rate the essay holistically on a scale of $0-4$, with 0 being "Poor" and 4 being "Excellent." This scale was selected in order to correspond with the traditional university grading scale, in which 0 is an $\mathrm{F}$ and 4 is an $\mathrm{A}$, and the prompt encourages respondents to consider this fact when making their rating.

Both essays presented to participants were adapted from Johnson and VanBrackle (2012), who found substantial differences in ratings of "standard" essays written by first-year undergraduate students and essays which contained features of African-American English. The "standard" essay used by Johnson and Van Brackle is authentic first-year undergraduate writing which was highly rated by anonymous raters who Johnson and VanBrackle indicate were almost certainly university English instructors. To create the second essay, Johnson and VanBrackle then modified this essay by including eight morphosyntactic features of African-American English which Whiteman (1981) and Smitherman (1977) posit appear in writing as well as speech. The AAE essay used in this study uses most of Johnson and VanBrackle's modifications; however, several of these modifications were deemed by the researcher, a native user of AAE, and another experienced sociolinguist, to be unnatural. Three of Johnson and VanBrackle's modifications were substituted and one additional feature was added, all of which are attested in the literature as AAE features which may appear in writing. For example, an instance of There be (unconjugated copula) was substituted with It's (existential it), which is more representative of naturally occurring AAE. These features were also selected because they are fairly unlikely to be interpreted as standard English mistakes. 
The final section of the survey aims to explore participants' attitudes toward the use of stigmatized varieties. First, in order to understand the weight that instructors place on spelling, punctuation, and morphosyntactic features generally, participants were asked how important these elements are in student writing and what the highest possible grade would be (on a scale of A-F) for an essay which was high-quality in terms of content and organization but contained noticeable spelling, punctuation, and grammar errors. Next, participants were asked whether they feel that features of "non-standard" varieties should be marked as errors in student writing. Finally, instructors were asked about the appropriateness of students" use of "non-standard" features in their academic writing. These questions were used both to develop a picture of English instructors' attitudes toward the use of stigmatized varieties of English in student writing and to investigate the relationship between instructors' conscious attitudes toward these varieties and their actual rating of essays containing features of these varieties.

2.3. ANALYSIS. An independent samples $t$-test and a Cohen's $d$ effect size were used to determine the effects of African-American English features on instructors' rating. Instructors' responses to the attitudes questions were analyzed qualitatively and supplemented by their responses to the open-ended follow-up questions.

3. Findings and discussion. The findings of this study indicate a substantial disconnect between university English instructors' rating of student writing which contains stigmatized features and their conscious attitudes toward the use of stigmatized features in student writing. These findings are detailed below in two sections. First, in section 3.1, I demonstrate the effect of the AfricanAmerican English (AAE) features on instructor rating. Then, in section 3.2, I present instructors' explicit answers to questions regarding the appropriateness of the use of AAE features and compare those conscious attitudes to their actual rating of student writing.

3.1. INSTRUCTOR RATING OF STUDENT WRITING. In total, 14 instructors participated in the survey, which yielded seven ratings of the unaltered essay and seven ratings of the essay with features of AAE. An independent samples $t$-test was used to compare instructors' ratings of the unaltered essay and the essay with AAE features and showed a statistically significant difference in instructor ratings of the two essays. On a scale of 0-4 (the standard university grading scale), the mean score of the unaltered essay was $3.0(\mathrm{SD}=0.58)$ while the mean score of the essay with AAE features was $2.17(\mathrm{SD}=0.69) ; \mathrm{t}(12)=2.52, \mathrm{p}=0.027$. Furthermore, Cohen's effect size value $(d=1.35)$ affirms the significant effect of AAE features on instructor rating. If we convert the mean scores to letter grades per the university scale (recall that the prompt encourages respondents to do so), the mean grade of the unaltered essay would be a mid-range $\mathrm{B}$, while the essay with features of AAE would receive a mid-range $\mathrm{C}$. These findings corroborate the results of Johnson \& VanBrackle's (2012) study in showing that instructors will more harshly grade an essay which differs only in that it contains features of AAE. A frequency distribution of the ratings of both essays is shown in Figure 1: 


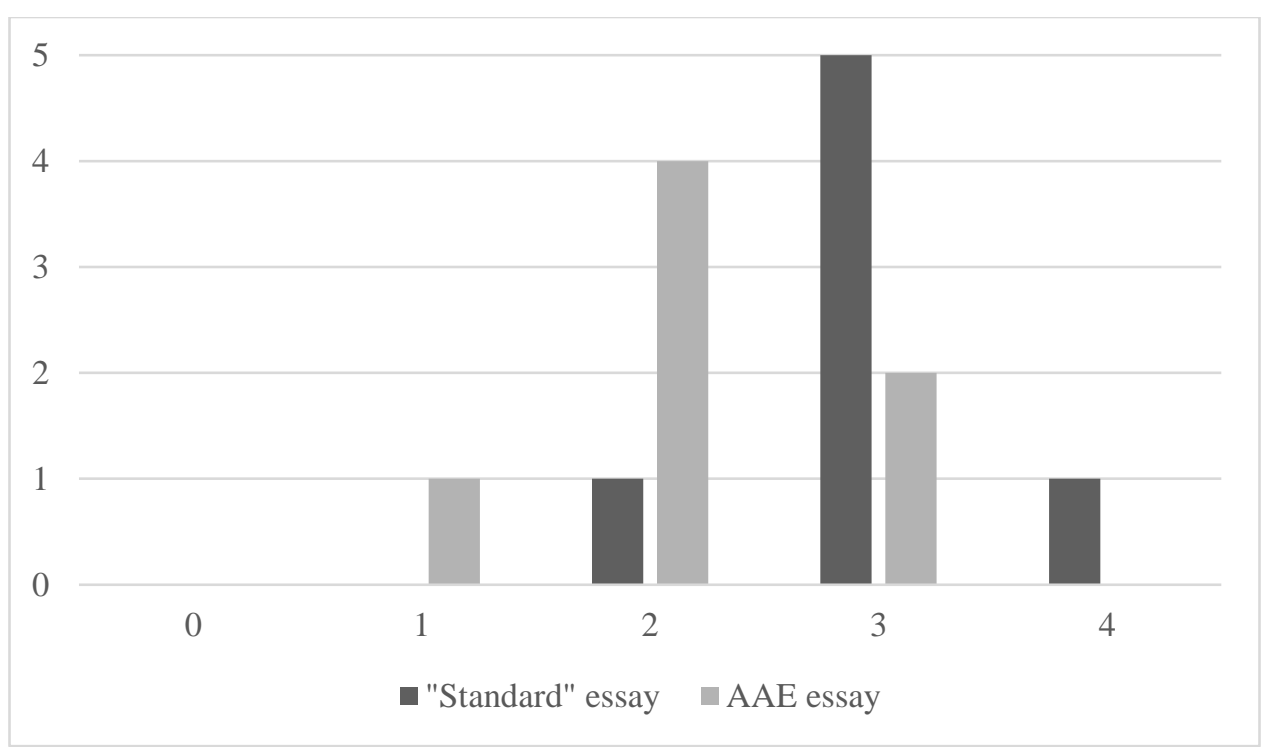

Figure 1. Instructor ratings of student writing.

3.2. INSTRUCTOR ATTITUDES TOWARD STIGMATIZED VARIETIES IN STUDENT WRITING. While the instructors in this study rated the essay with AAE features lower, their conscious beliefs about the use of stigmatized varieties in student writing seem to predict the opposite. When asked whether features of stigmatized varieties should be marked as errors in student writing, the vast majority of respondents indicated that they should not, with only one respondent selecting "probably yes." A frequency distribution of instructors' responses regarding the treatment of features of stigmatized varieties as errors are shown in Figure 2.

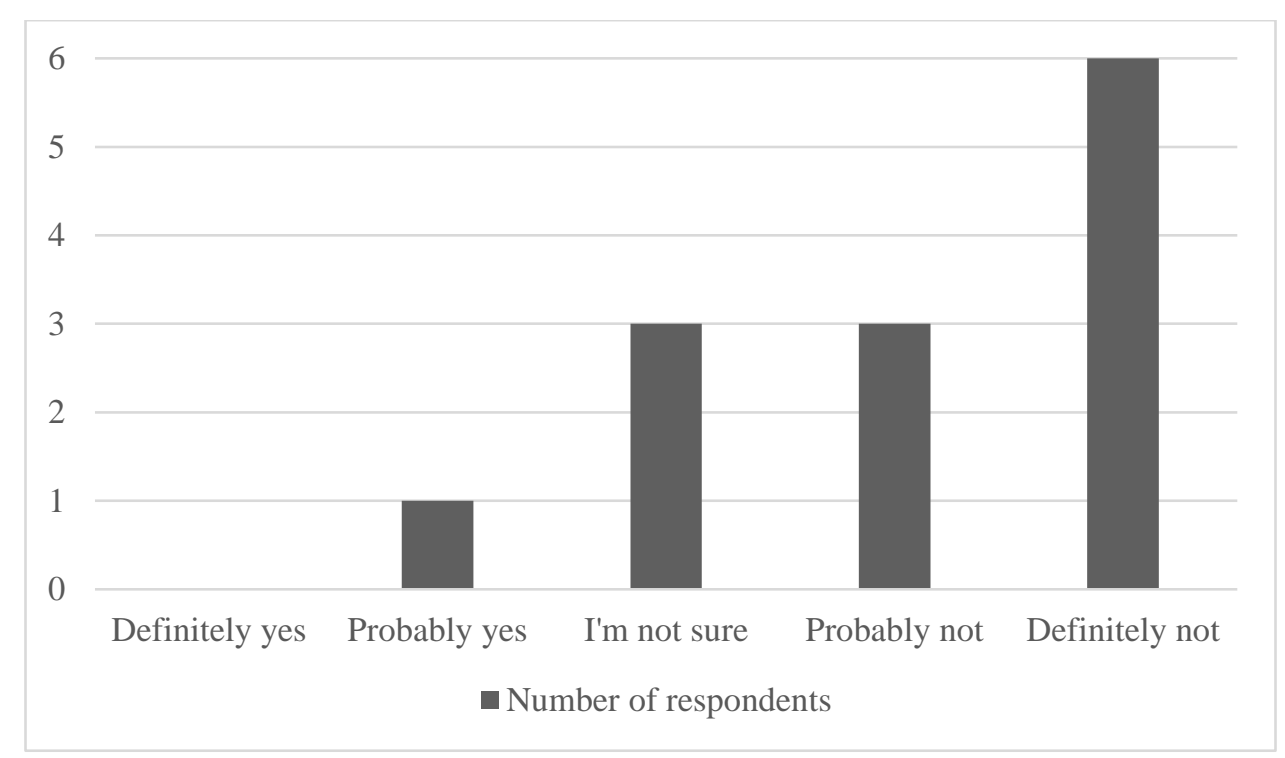

Figure 2. Instructor responses regarding treatment of non-standard features as errors. ${ }^{1}$

When asked about the appropriateness of stigmatized varieties in student writing, instructors responded even more positively, and no respondent indicated that the use of a

${ }^{1}$ The full question reads: "Should features of non-standard varieties (e.g. African-American English, Chicano English, Southern English, etc.) of English be marked as errors in student writing?" 
student's variety in their writing would be inappropriate to any degree. A frequency distribution of instructors' responses regarding the appropriateness of the use of a stigmatized variety in student writing is shown in Figure 3.

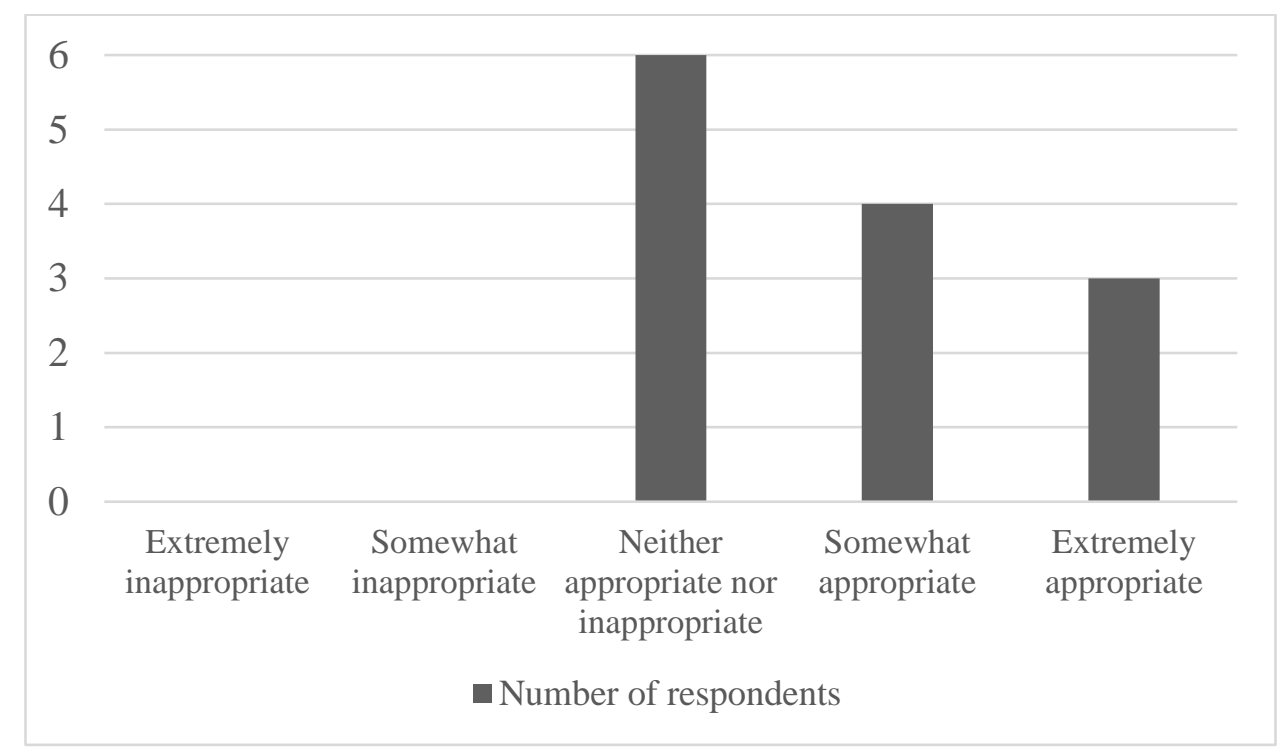

Figure 3. Instructor responses regarding student usage of non-standard features in writing. ${ }^{2}$

Both of these attitudes questions also offered respondents an opportunity to explain their rating, and every respondent offered at least one sentence to explain their answers. Like the ratings, these responses revealed highly positive and culturally sensitive attitudes toward the use of stigmatized varieties in student writing. In response to the first attitudes question regarding the marking of "non-standard" features as errors, the vast majority of instructors strongly advocated students' use of their own "voice," or features of their variety. In addition, nearly all of the instructors, including the respondent who indicated that non-standard features should "probably" be marked as errors, claimed that the use of stigmatized features simply depends on the genre of writing and the expectations of the instructor. Similarly, in response to the second attitudes question regarding appropriateness of use, instructors either referred to their previous answer or reiterated the appropriateness of the use of "non-standard" varieties. Furthermore, two respondents, one of whom indicated that the use of non-standard varieties is "extremely appropriate," and another who indicated that it is "somewhat appropriate," explicitly stated that the treatment of non-standard varieties as errors would be racist and should never happen, as seen in the response of the instructor who deemed the use of these features "extremely appropriate":

By asking students to write like white, middle-class folk and calling that dialect "academic," we'd be reinforcing the structures that make it a whole lot easier for white, middle-class folk to succeed.

Interestingly, both of these respondents were presented with the essay containing AAE features, and both of these respondents gave the essay a rating of 2 , or a $\mathrm{C}$ on the university grading scale.

\footnotetext{
${ }^{2}$ The full question reads: "How appropriate is it for students who speak a non-standard variety of English to use features of their variety in their academic writing?"
} 
This dissonance between instructors' ratings of the essays and their attitudes toward stigmatized varieties may be the result of a lack of knowledge about what "non-standard" varieties look like in writing, especially in comparison to errors of "standard" written English.

4. Conclusions and implications. The findings of this study suggest that although university English instructors are consciously well-intentioned about linguistic diversity, they may nevertheless be influenced by standard language ideology and this influence may manifest itself in significant grade reductions for students who use stigmatized varieties of English in their writing. It is possible, as one reviewer suggested, that these instructors recognized features of AAE and downgraded that essay intentionally but made positive statements about stigmatized varieties under the pressure of political correctness. However, given these instructors' highly positive comments about students' use of their own variety and my own experience with these instructors' efforts to promote and protect diversity on campus, I find this explanation unlikely, at least for these instructors.

In order to provide a safe and equitable learning environment and to set a good example for the broader populace, many of whom look to academia for prescriptive standards, it is essential that we continue to investigate university instructors' attitudes toward stigmatized varieties of English and ensure that instructors have the resources they need in order to support speakers of all varieties of English.

4.1. IMPLICATIONS FOR PRACTICE. This study corroborates the findings of Johnson and VanBrackle (2012) in showing that the inclusion of features of stigmatized varieties in student writing may result in significantly lower ratings. Furthermore, Dunstan and Jaeger (2015) found that students who speak stigmatized varieties are aware of peers' and instructors' attitudes toward their variety of English, and felt that their use of their own variety often substantially affected their academic identity and performance. Thus, although the research in this area is still fairly sparse, it appears that linguistic discrimination on university campuses is prevalent and has a meaningful effect on students.

In order to begin proactively addressing these concerns, Dunstan and Jaeger suggest that it is essential to begin "educating faculty, staff, and administrators on language diversity" (796), an endeavor which Walt Wolfram has spearheaded to substantial success at the University of North Carolina. Such education is uniquely important for English instructors like those examined in this study for several reasons. First, every undergraduate student (except for those who have passed Advanced Placement or College Level Examination Program tests) must take first-year composition. This mandatory interaction provides an opportunity for English instructors to inform students who use stigmatized varieties of the prevalence of standard language ideology and prepare them for their academic career by teaching about things like audience, purpose, and genre rather than about the use of a single correct variety of English. Second, all of the English instructors who participated in this study held strong beliefs about the empowerment and encouragement of students' use of their own variety. These instructors can be early, powerful advocates for students who use stigmatized varieties, and can also help to dispel myths about language variation across campus and among the general public, who often look to English instructors as the final authority on language matters. 
4.2. IMPLICATIONS FOR FUTURE RESEARCH. In addition to showing the significant need for dialect education at the university level, the findings of this study, which align closely with the few other studies on the matter, highlight the need for continued research into the effects of stigmatized varieties on instructors' treatment of student writing. Although discrimination on a linguistic basis at the university level is clearly an issue, to my knowledge, Johnson and VanBrackle (2012) is the only other study which investigates the effects of discrimination on instructor rating, although their study used only anonymous raters. Furthermore, only Dunstan and Jaeger (2015) have explored the effects of linguistic discrimination on students from a student perspective. The present study attempts to begin filling this gap in the research on standard language ideology at the university by focusing on a specific population of instructors and by investigating their explicit attitudes toward stigmatized varieties.

There are several limitations in the present study. First, the sample size is small, and is comprised only of graduate students who are teaching assistants in the English department at one university. Although this limited sample does allow for a focused investigation of English instructors (a population for whom this issue is especially important as described above in section 4.1) students do, of course, interact with and receive grades on writing assignments from instructors in a broad range of other disciplines during their university career. Future research should broaden the sample to include other instructors in the English department including fulltime faculty, and to instructors in other departments across the university.

In addition to the limited sample size, the modified essay in this study only included features from one stigmatized variety, African-American English. There are, of course, students who speak many other stigmatized varieties at universities, including Chicano English and Southern English. It may be the case that attitudes toward one variety or another may vary based on region, the percentage of students in a university population who use a certain variety, or other factors. Future research could incorporate other varieties, especially varieties which are more prevalent at a particular university (e.g. stigmatized regional varieties).

This study represents an important expansion of our awareness that university instructors, including those who teach language and promote diversity both in and out of the classroom, are not immune to the effects of standard language ideology and linguistic discrimination, and that this may result in substantial effects on students, including in their grades. However, this study has also found that many English instructors are aware of and hold highly positive beliefs about the use of one's own variety in academic writing, and have considered how to teach users of stigmatized varieties to write in academia. This is an encouraging finding and one which suggests that, with some dialect education, English instructors are prepared to be a powerful force in dispelling the standard language ideology so prevalent at the university level and more broadly in American culture. 


\section{References}

Creswell, John W. 2013. Research design: Qualitative, quantitative, and mixed methods approaches. London: SAGE publications.

Dunstan, Stephany Brett \& Audrey J. Jaeger. 2015. Dialect and influences on the academic experiences of college students. The Journal of Higher Education 86(5). 777-803. https://doi.org/10.1353/jhe.2015.0026.

Eustace, Elizabeth. 2012. Speaking allowed? Workplace regulation of regional dialect. Work, Employment \& Society 26(2). 331-348. https://doi.org/10.1177/0950017011432912.

Johnson, David \& Lewis VanBrackle. 2012. Linguistic discrimination in writing assessment: How raters react to African American "errors," ESL errors, and standard English errors on a state-mandated writing exam. Assessing Writing 17(1). 35-54. https://doi.org/10.1016/j.asw.2011.10.001.

Kroll, Tobias A., Zaneta Mok, Louise Keegan, Ioannis Papakyritsis, \& Jack S. Damico. 2014. Acadiana-Area Speech-Language Pathology Students' Perceptions of Cajun English Speakers. Contemporary Issues in Communication Science \& Disorders, 41. 210-220.

Lippi-Green, Rosina. 1997. English with an accent: Language, ideology, and discrimination in the United States. New York: Routledge

Milroy, James \& Leslie Milroy. 2012. Authority in language: Investigating Standard English. New York: Routledge.

Smitherman, Geneva. 1977. Talkin and testifyin: The language of black America. Detroit, MI: Wayne State University Press.

Whiteman, Marcia Farr. 1981. Dialect influence in writing. In Marcia Farr Whiteman (ed.), Variation in writing: Functional and linguistic cultural differences. Hillsdale, N.J.: Lawrence Erlbaum Associates. 
Appendix A - Essays

\section{Original Essay}

\section{Is increased life expectancy a blessing or a curse?}

As modern technology improves, so does our life expectancy. Every year people live longer due to the knowledge that medical science has gained. Some might wonder if this gain is a blessing or a curse. There are many reasons why it could be either one, but with proper planning, one could live a long and enjoyable lifetime.

An important factor to living a long life is eating and living healthy. Studies have shown that a low fat, high fiber diet full of plenty of fruits and vegetables will not only make you look and feel healthy, but will also increase your longevity. Walking just thirty minutes a day can vastly improve your cardiovascular system, which is essential to living a long life.

Another important step to take if you want to comfortably live to a ripe old age is to plan financially. Even though our government saves social security benefits for each of us, it is barely enough to survive. One must begin planning for retirement as early as their twenties with 401 K's and savings plans. My father's company was able to help with this retirement planning.

Some might argue that they don't want to live to be ninety or one hundred. They don't want to watch all their friends and family die around them. These people must remember that even though they must witness many deaths of loved ones, they will also see many joyous births of new beautiful babies that will enrich their lives and fill them with joy and happiness. They will also be fortunate enough to experience a lot of history, and if they planned well financially, see a lot of the world as well. These experiences will make them wise and worldly.

Some might argue that they are worried that when they get extremely old, their body will deteriorate. They are scared that their vision will go bad, as well as their hearing. They are worried their bones and muscles will crack and ache. They are afraid their mobility will be challenged. For these people, I suggest practicing yoga or another form of daily stretching to keep their body in top shape. Make sure and eat plenty of vitamins and drink lots of water every day. You should not smoke, and you should keep alcohol consumption to a minimum.

A long life can be a wonderful blessing. Throughout a long lifetime, one can witness many great historical moments and learn many great things. If you want to live a long, healthy life, be sure to plan for it properly by taking care of your finances, enriching your mind, and most importantly, taking care of your body and soul.

\section{AAE Essay (bold not present in survey)}

Is increased life expectancy a blessing or a curse?

As modern technology improve, so does our life expectancy. Every year people live longer due to the knowledge that medical science has gained. Some might wonder if this gain is a blessing or a curse. It's many reasons why it could be either one, but with proper planning, one could live a long and enjoyable lifetime. 
An important factor to living a long life is eating and living healthy. Studies have shown that a low fat, high fiber diet full of plenty of fruits and vegetables will not only make you look and feel healthy, but will also increase your longevity. Walking just thirty minutes a day can vastly improve your cardiovascular system, which is essential to living a long life.

Another important step to take if you want to comfortably live to a ripe old age is to plan financially. Even though our government save social security benefits for each of us, it is barely enough to survive. One must begin planning for retirement as early as their twenties with 401 K's and savings plans. My father company was able to help with this retirement planning.

Some might argue that he don't want to live to be ninety or one hundred. They want to watch all their friends and family die around them. These people must remember that even though they must witness many deaths of loved ones, they will also see many joyous births of new beautiful babies that will enrich their lives and fill them with joy and happiness. They will also be fortunate enough to experience a lot of history, and if they planned well financially, see a lot of the world as well. These experiences will make them wise and worldly.

Some might argue that they are worried that when they get extremely old, their body will deteriorate. They scared that their vision will go bad, as well as their hearing. They are worried their bones and muscles will crack and ache. They are afraid their mobility gone be challenged. For these people, I suggest practicing yoga or another form of daily stretching to keep their body in top shape. Make sure and eat plenty of vitamin and drink lots of water every day. You should not smoke, and you should keep alcohol consumption to a minimum.

A long life can be a wonderful blessing. Throughout a long lifetime, one can witness many great historical moments and learn many great things. If you want to live a long, healthy life, be sure to plan for it properly by taking care of your finances, enriching your mind, and most importantly, taking care of your body and soul.

\section{AAE Modifications:}

1. As modern technology improve, so does our life expectancy. (absence of third-person $-s$ )

2. It's many reasons why it could be either one, but... (existential it)

3. ...but will also increase longevity for hisself. (hisself for himself)

4. Even though our government save social security benefits for each of us... (absence of third-person $-s$ )

5. My father company was able to help with this retirement planning. (absence of possessive - 's)

6. Some might argue that he don't want to live to be ninety or one hundred. (don't for doesn't)

7. They scared that their vision will go bad, as well as their hearing. (copula absence)

8. They are afraid their mobility gone be challenged. (gone for will)

9. Make sure and eat plenty of vitamin... (absence of plural $-s$ ) 